\title{
ANALISIS DAN PERANCANGAN APLIKASI SIMPAN PINJAM PADA KOPERASI PEGAWAI PT. UNZA VITALIS
}

\author{
Muhammad Fikri \\ Teknik Informatika, Fakultas Teknik dan Ilmu Komputer, Universitas Indraprasta PGRI Jakarta \\ Jalan Raya Tengah No 80, Kelurahan Gedong, Pasar Rebo, Jakarta Timur \\ muhamadfikrimm41@gmail.com
}

\begin{abstract}
ABSTRAK
Permasalahan yang terdapat pada PT. Unza Vitalis yaitu proses pencatatan baik itu data anggota, data simpan dan data pinjaman memakan waktu lama, karena dalam melakukan pencatatan dan pengolahan data yang dilakukan dengan cara ditulis dan diarsipkan dalam buku atau dokumen koperasi bisa memakan waktu hingga berjam-jam. Tujuan merancang suatu aplikasi simpan pinjam koperasi pegawai ini dengan tujuan untuk memudahkan admin dalam memproses pengolahan data yang ada saat ini. Perangkat aplikasi yang telah dibuat dengan bahasa pemrograman Java NetBeans 8.0.2 dan penyimpanan data pada database MySQL dapat memberikan kelancaran dalam proses menginput dan penyimpanan data-data serta laporan-laporan yang diberikan kepada pimpinan perusahaan. Dengan menggunakan metode pengembangan sistem yaitu Waterfall dalam penelitian ini adalah dengan tahapan-tahapan seperti rekayasa sistem, analisis, desain, coding, testing, dan maintenance. Hasil dari penelitian ini menciptakan suatu aplikasi ini memberikan fungsi dalam mengelola data administrasi dan simpan pinjam koperasi sehingga aplikasi ini dapat memeriksa jumlah pinjaman anggota serta memudahkan admin koperasi dalam memberikan laporan kepada pimpinan.
\end{abstract}

Kata Kunci: Aplikasi, Koperasi, Simpan Pinjam, Desktop

\begin{abstract}
The problems that exist in PT. Unza Vitalis, namely the recording process, whether it's member data, saving data and loan data, takes a long time, because recording and processing data is done by writing and filing in books or cooperative documents it can take up to hours. The purpose of designing an employee cooperative savings and loan application is to make it easier for the admin to process the current data processing. Application tools that have been created using the Java NetBeans 8.0.2 programming language and data storage in the MySQL database can provide smooth processing of input and storage of data and reports provided to company leaders. By using the system development method, namely Waterfall, in this research, the stages are systems engineering, analysis, design, coding, testing, and maintenance. The results of this study create an application that provides functions in managing administrative data and cooperative savings and loans so that this application can check the loan amount of members and make it easier for the cooperative admin to provide reports to the leadership.
\end{abstract}

Key Word: Application, Cooperative, Saving and Loan, Desktop

\section{PENDAHULUAN}

Koperasi berasal dari kata: Co dan operation, Co berarti bersama dan operation berarti kegiatan/pekerjaan. Dari dua kata tersebut pengertian dasarnya menjadi "Bersama-sama melakukan kegiatan atau pekerjaan untuk mencapai suatu tujuan bersama, secara demokratis, terbuka dan sukarela" (Subyantoro, 2015). Ciri utama koperasi adalah kerja sama anggota dengan tujuan untuk mencapai kesejahteraan hidup bersama. Terdapat bermacam-macam definisi koperasi dan jika diteliti secara seksama, maka tampak bahwa definisi itu berkembang sejalan dengan perkembangan jaman (Astuti \& Devitra, 2017).
Definisi awal pada umumnya menekankan bahwa koperasi itu merupakan wadah bagi golongan ekonomi lemah, seperti ekonomi yang menyatakan koperasi adalah suatu perserikatan dengan persetujuan berusaha bersama yang terdiri atas mereka yang lemah dan diusahakan dengan selalu semangat tidak memikirkan diri sendiri sedemikian rupa, sehingga masing-masing sanggup menjalankan kewajibannya sebagai anggota dan mendapat imbalan sebanding dengan pemanfaatan mereka terhadap organisasi (Puspitasari, 2016).

Salah satu faktor penting untuk meningkatkan kinerja koperasi yang baik adalah adanya peran Pemerintah karna koperasi merupakan 
tulang punggung perekonomian Indonesia. Dalam pasal 33 UUD 1945 dinyatakan bahwa "Perekonomian Indonaesia disusun sebagai usaha bersama berdasarkan asas kekeluargaan" (Atikah \& Sukadi, 2013). Dalam penjelasan UUD 1945 disebutkan bahwa badan usaha yang sesuai dengan pasal tersebut adalah koperasi, sehingga koperasi ditempatkan sebagai soko guru perekonomian Indonesia dan merupakan bagian integral perekonomian Indonesia (Sujono, Mayasari, \& Koloniawan, 2019).

Ada beberapa macam lembaga koperasi yang berdiri atau berkembang dilingkungan masyarakat, salah satunya Lembaga Keuangan Syariah (LKS) yang saat ini tumbuh dengan cepat dan menjadi bagian dari kehidupan keuangan di dunia islam. LKS bukan hanya terdapat di negara-negara Islam, tetapi juga terdapat di negara-negara yang ada masyarakat musliminnya. LKS di Indonesia telah menunjukan perkembangan pesat selama dekade terakhir ini. Disamping adanya dukungan pemerintah dan sambutan positif umat Islam yang besar, LKS terbukti secara empiris tetap bertahan dalam kondisi krisis ekonomi yang telah memporak-porandakan sendi-sendi ekonomi dan sosial masyarakat. Kondisi dan tingkat pertumbuhan ekonomi memunculkan perkembangan lembagalembaga keuangan syariah (Wati \& Siahaan, 2017).

Koperasi Simpan Pinjam Pegawai PT. Unza Vitalis merupakan balai usaha mandiri terpadu yakni lembaga usaha yang mengembangkan aspek-aspek produksi dan investasi untuk meningkatkan kualitas kegiatan ekonomi dalam sekala kecil dan menengah. Koperasi Simpan Pinjam Pegawai PT. Unza Vitalis sebagai koperasi syariah yakni lembaga ekonomi yang berfungsi untuk menarik, mengelola, dan menyalurkan dana dari oleh dan untuk kita. Oleh karena itu koperasi ini dapat disebut sebagai swadaya ekonomi umat yang dibentuk, dari, oleh dan untuk kita.

Sebagai lembaga bisnis, Koperasi Simpan Pinjam Pegawai PT. Unza Vitalis lebih mengembangkan usahanya pada sektor keuangan, yakni simpan pinjam, produk pinjaman berupa pembiayaan. Pembiayaan yang ada pada koperasi di PT. Unza Vitalis yaitu pembiayaan Mudharabah. Dalam simpan pinjam koperasi di PT. Unza Vitalis masih ditemui beberapa permasalahan yang memperlambat kinerja koperasi dalam penginputan administrasi keanggotaan simpan pinjam, penyimpanan data fisik yang masih belum tertata secara rapih dan teratur, hal tersebut dapat dilihat dari bagaimana proses transaksi simpan, pinjam, dan pembayaran angsuran. Penginputan tersebut masih menggunakan sistem yang belum terkomputerisasi sehingga sering terjadi kesalahan pencatatan, arsip yang sulit dicari dan masalah lainnya. Minimnya jumlah pengolahan koperasi juga menjadi salah satu faktor yang dapat memperlambat kinerja penginputan administrasi keanggotaan.

Dengan permasalahan tersebut, perlu ada nya suatu sistem yang terkomputerisasi dalam penyelesaiannya. Sistem adalah sekelompok unsur yang erat hubungannya satu dengan yang lain, yang berfungsi bersama-sama untuk mencapai tujuan (Sutabri, 2012). Sistem merupakan suatu kumpulan dari komponen-komponen yang membentuk satu kesatuan (Tyoso, 2016). Pembangunan sistem adalah sekumpulan aktivitas yang menggambarkan secara rinci bagaimana sistem akan berjalan. Hal itu bertujuan untuk menghasilkan produk perangkat lunak yang sesuai dengan kebutuhan user (Satzinger, J. W., Jackson, R. B., Burd, n.d.).

Diharapkan dengan adanya suatu sistem informasi dapat menangani permasalahan yang ada di perusahaan tersebut. Sistem adalah setiap sesuatu terdiri dari obyek-obyek, atau unsur-unsur, atau komponen-komponen yang bertata kaitan dan bertata hubungan satu sama lain, sedemikian rupa sehingga unsurunsur tersebut merupakan satu kesatuan pemrosesan atau pengolahan yang tertentu. (Prasojo, 2011)

Penelitian terdahulu dengan peneliti (Permana, 2017) memiliki hasil penelitian Sistem informasi yang baik diperlukan untuk membantu dan mengawasi kegiatan simpan pinjam, sehingga dapat mengikuti perkembangan usaha yang sedang berkembang. Koperasi Guru dan Pegawai SMP Negeri 45 Jakarta memerlukan suatu perancangan sistem informasi yang akan membantu karyawannya dalam menangani administrasi simpan pinjam. Pada penelitian 
ini, suatu sistem komputerisasi simpan pinjam pada Koperasi Guru dan Pegawai SMP Negeri 45 Jakarta yang sesuai berhasil dibuat dan dirancang untuk mendukung berkembangnya koperasi tersebut.

Aplikasi ini dapat memudahkan pekerjaan petugas koperasi perusahaan dalam melaksanakan pembuatan laporan dan mempercepat dalam proses data pencarian data anggota koperasi, data simpanan, data pencairan, data pembayaran serta data pinjaman pada koperasi pegawai PT. Unza Vitalis.

\section{METODE PENELITIAN}

Peneliti menggunakan metode Research and Development daam penyelesaian penelitian ini. (Sugiyono, 2016). Dalam pelaksanaan $\mathrm{R} \& \mathrm{D}$, ada beberapa metode yang digunakan yaitu metode deskriptif, evaluatif dan eksperimental. Metode penelitian deskriptif digunakan dalam penelitian awal untuk menghimpun data tentang kondisi yang ada yaitu penulis membutuhkan data-data yang dapat menunjang tercipta nya suatu sistem informasi usaha simpan pinjam koperasi seperti data anggota, data simpanan, data pinjaman dan data pembayaran angsuran terdahulu yang masih tersimpan secara manual didalam buku besar. Metode evaluatif digunakan untuk mengevaluasi proses ujicoba pengembangan suatu produk, dalam proses ini penulis melakukan ujicoba terhadap suatu sistem yang telah dirancang agar tidak ada terjadi kesalahan dalam proses penginputan data serta pelaporan bulanan kepada kepala koperasi. Dan metode eksperimen digunakan untuk menguji keampuhan dari produk yang dihasilkan, dalam proses yang terakhir ini perlu dilakukan pengujian akhir yang diharapkan bahwa sistem yang dirancang oleh penulis dapat berjalan dengan baik dan sesuai dengan kebutuhan dan terfokus pada proses simpan pinjam koperasi pegawai PT. Unza Vitalis (Putra, 2011).

\section{HASIL DAN PEMBAHASAN}

\section{Alternatif Penyelesaian Masalah}

Pemecahan masalah merupakan suatu tindakan yang harus dilaksanakan dalam menghadapi permasalahan yang ada pada PT. Unza Vitalis, berdasarkan hasil Analisis dan uraian umum tentang sistem yang sedang berjalan maka harus dicari alternatif penyelesaian masalah agar dapat dilakukan perbaikan-perbaikan ke arah positif sehingga dapat menunjang koperasi dalam peningkatan kerja. Berikut uraian dari penyelesaian masalah yang diharapkan:

1. Perlu adanya aplikasi sistem informasi yang terkomputerisasi sehingga dapat memperbaiki kinerja PT. Unza Vitalis khususnya dalam bagian koperasi simpan pinjam pegawai, peminjaman dana dan pembayaran.

2. Proses pengolahan data pada admin lebih efisien, tepat dan akurat.

3. Dalam proses penginputan data dari anggota yang hendak melakukan peminjaman tidak lagi menggunakan sistem manual namun sudah terkomputerisasi.

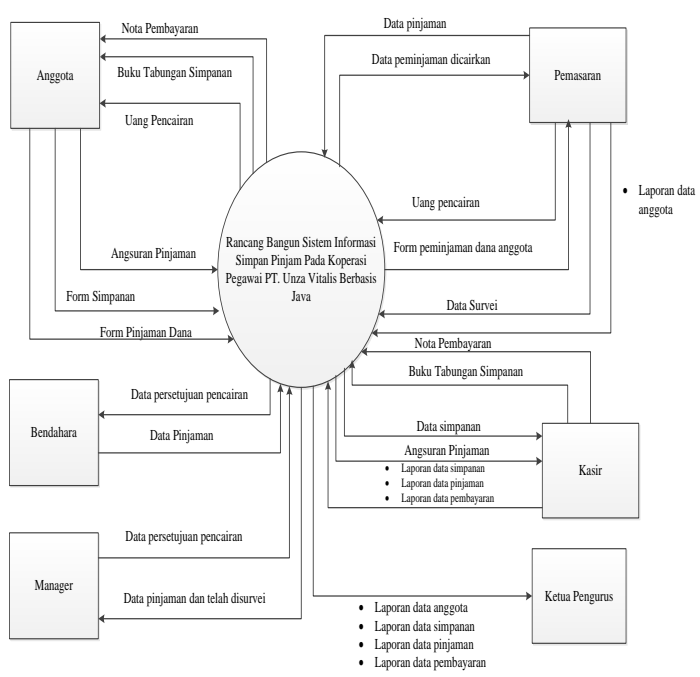

Gambar 1. Diagram Konteks

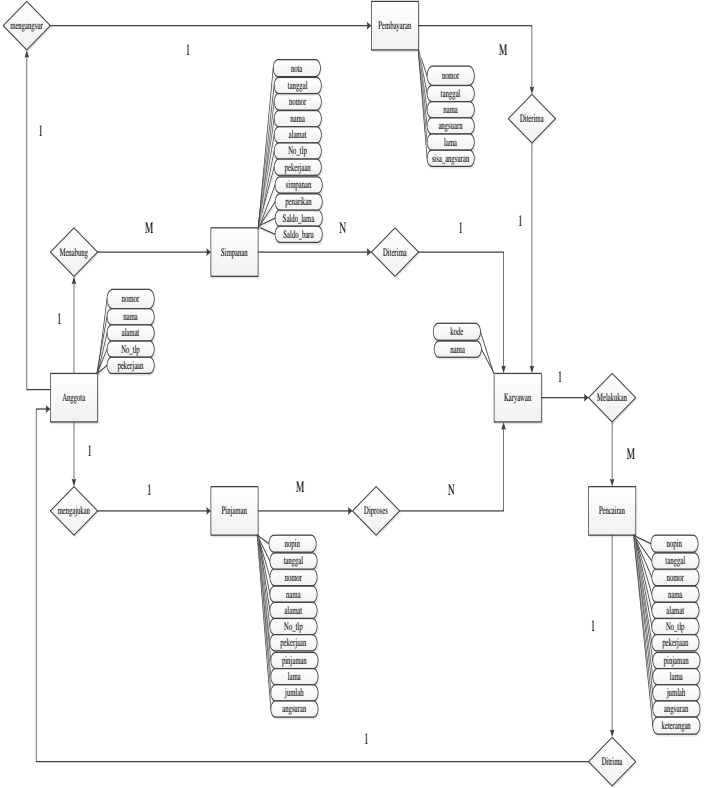

Gambar 2. ERD (Entity Relationship Diagram) 
Berikut adalah tampilan layar dan hasil pengujian pada software program yang telah di buat dengan bahasa pemrograman Java.

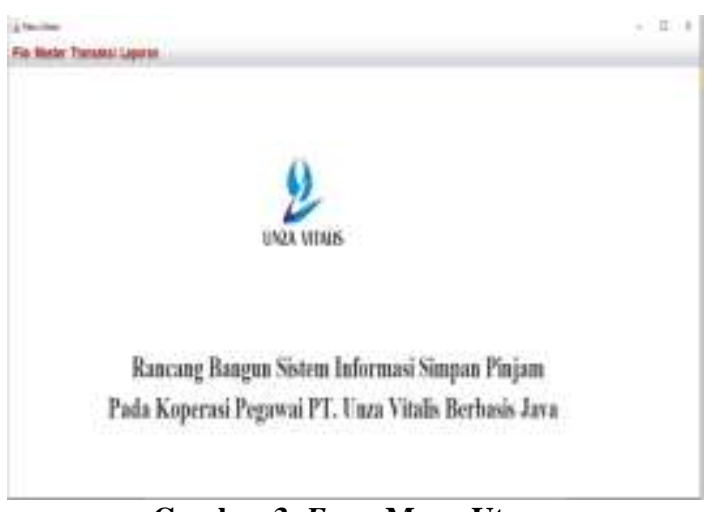

Gambar 3. Form Menu Utama

Layar di atas menampilkan tampilan Menu Utama pada Sistem Informasi Koperasi Simpan Pinjam Pegawai PT. Unza Vitalis. Pada layar utama tersedia menu bar yang terdiri dari master data yang digunakan untuk memasukkan data yang berkaitan dengan data anggota, data simpanan, data pinjaman, data pembayaran dan laporan-laporan.

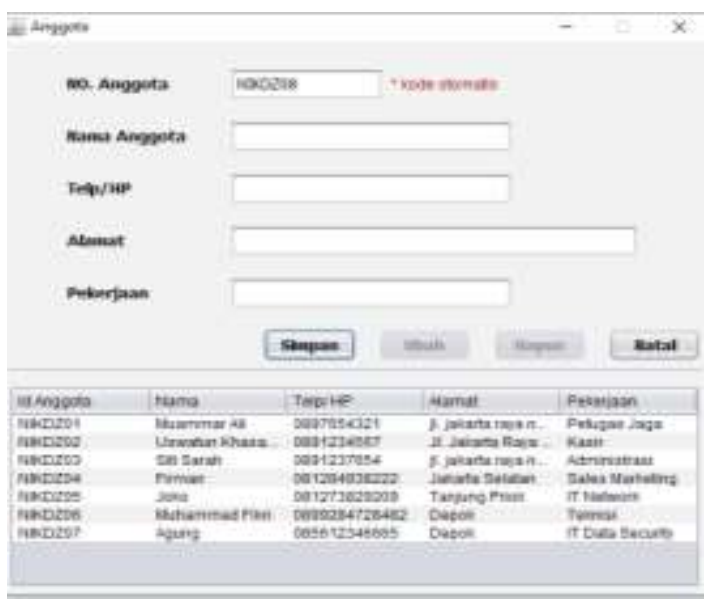

Gambar 4. Form Data Anggota

Layar di atas menampilkan tampilan form data anggota. Pada layar form data anggota untuk meng-input data barang yang terdiri dari ID Anggota, Nama Anggota, Telp, Alamat dan Pekerjaan.

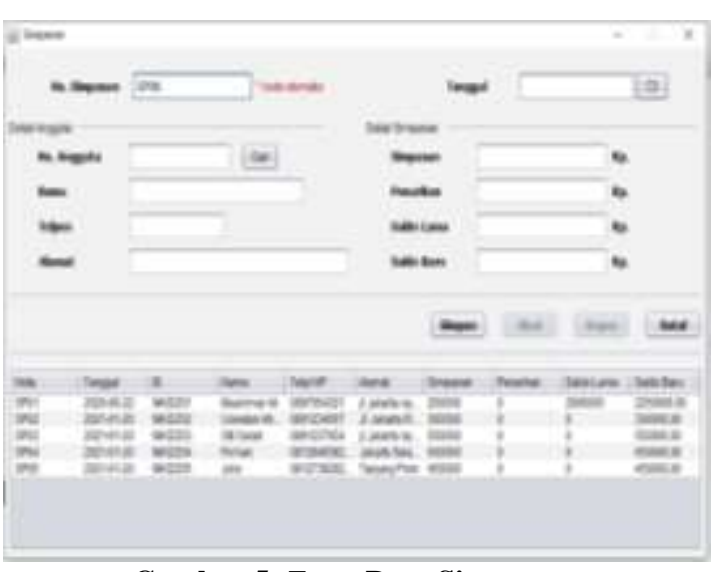

Gambar 5. Form Data Simpanan

Layar di atas menampilkan tampilan form data simpanan. Pada layar form data simpanan untuk meng-input data gudang yang terdiri dari No Simpanan, Tgl Simpanan, No Anggota, Nama Anggota, No Telp, Alamat, Simpanan, Penarikan, Saldo Lama dan Saldo Baru.

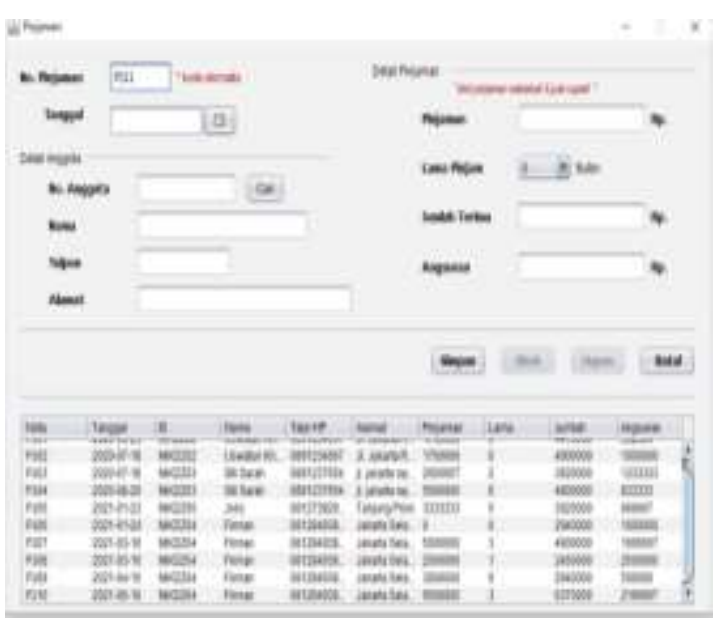

Gambar 6. Data Form Data Pinjaman

Layar di atas menampilkan tampilan form data pinjaman. Pada layar form data pinjaman untuk meng-input data pinjaman yang terdiri dari No Pinjaman, Tgl Pinjaman, No Anggota, Nama Anggota, No Telp, Alamat, Pinjaman, Lama Pinjaman, Jumlah Terima dan Angsuran. 


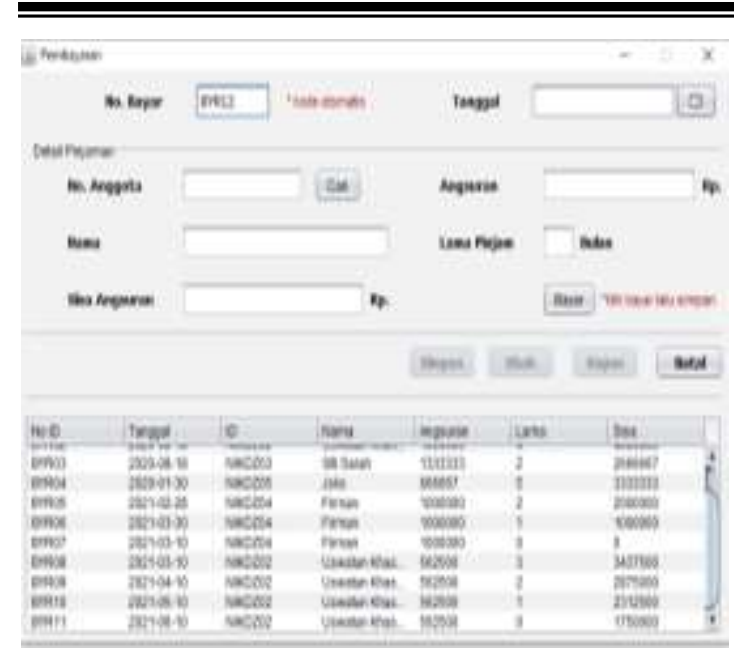

Gambar 7. Form Data Pembayaran

Layar di atas menampilkan tampilan form data pembayaran. Pada layar form data pembayaran untuk meng-input data pembayaran yang terdiri dari No Bayar, Tgl Bayar, No Anggota, Nama Anggota, Sisa Angsuran, Angsuran dan Lama Pinjam.

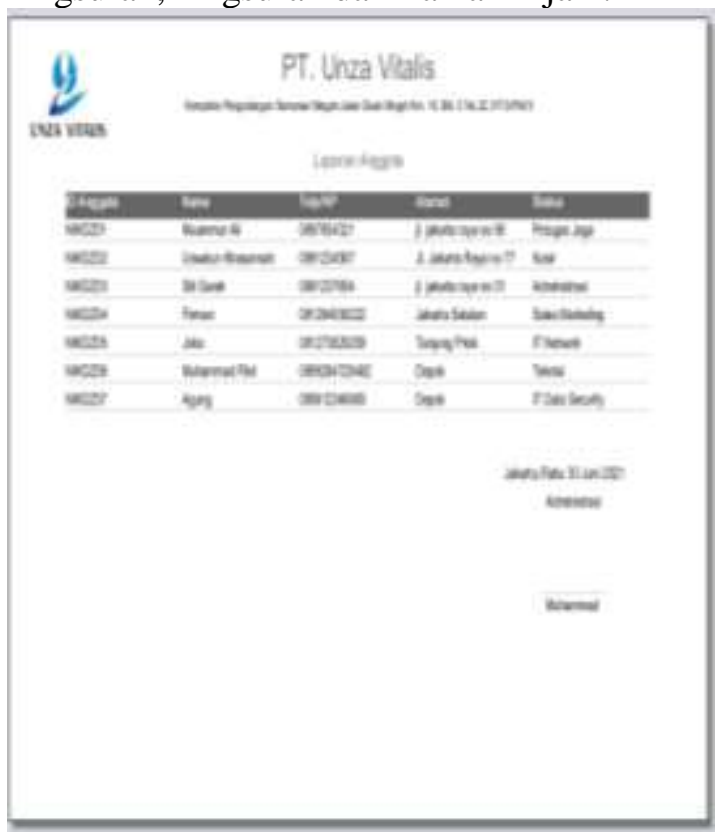

Gambar 8. Laporan Data Anggota

Layar di atas menampilkan tampilan form laporan data anggota. Pada layar form data anggota masuk digunakan untuk mengecek laporan data anggota masuk terdiri ID Anggota, Nama Anggota, No Telp, Alamat, dan Pekerjaan.

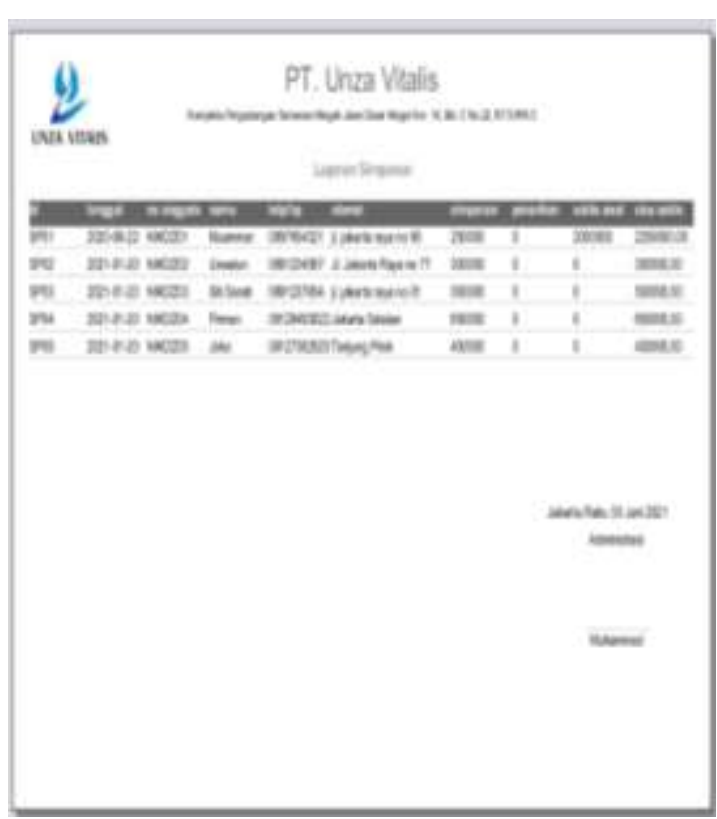

Gambar 9. Laporan Data Simpanan

Layar di atas menampilkan tampilan form laporan data simpanan. Pada layar form data simpanan digunakan untuk mengecek laporan data simpanan terdiri No Simpanan, Tgl Simpanan, No Anggota, Nama Anggota, No Telp, Alamat, Simpanan, Penarikan, Saldo Awal dan Sisa Saldo.

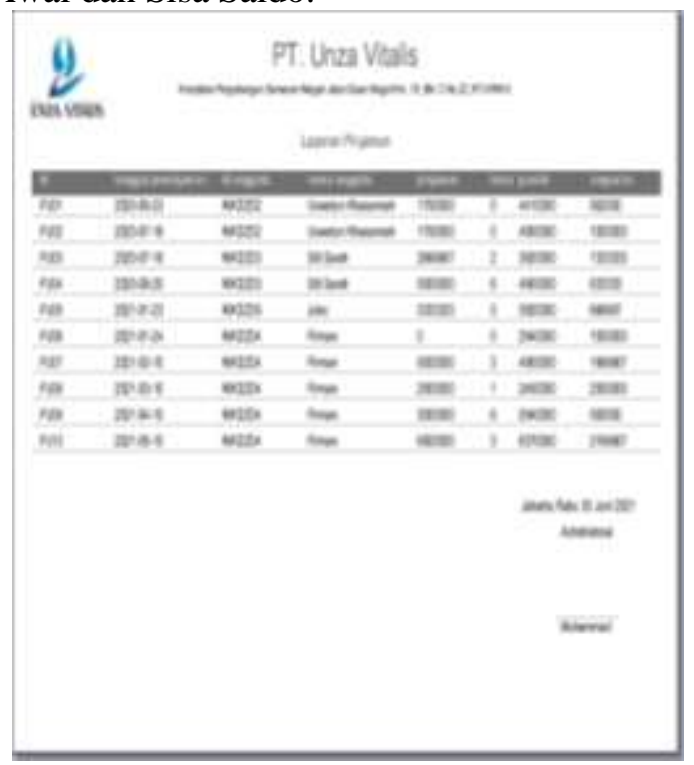

Gambar 10. Laporan Data Pinjaman

Layar di atas menampilkan tampilan form laporan data pinjaman. Pada layar form data pinjaman digunakan untuk mengecek laporan data pinjaman terdiri No Pinjaman, Tgl Pinjaman, No Anggota, Nama Anggota, No Telp, Alamat, Pinjaman, Lama Pinjaman, Jumlah Terima dan Angsuran. 


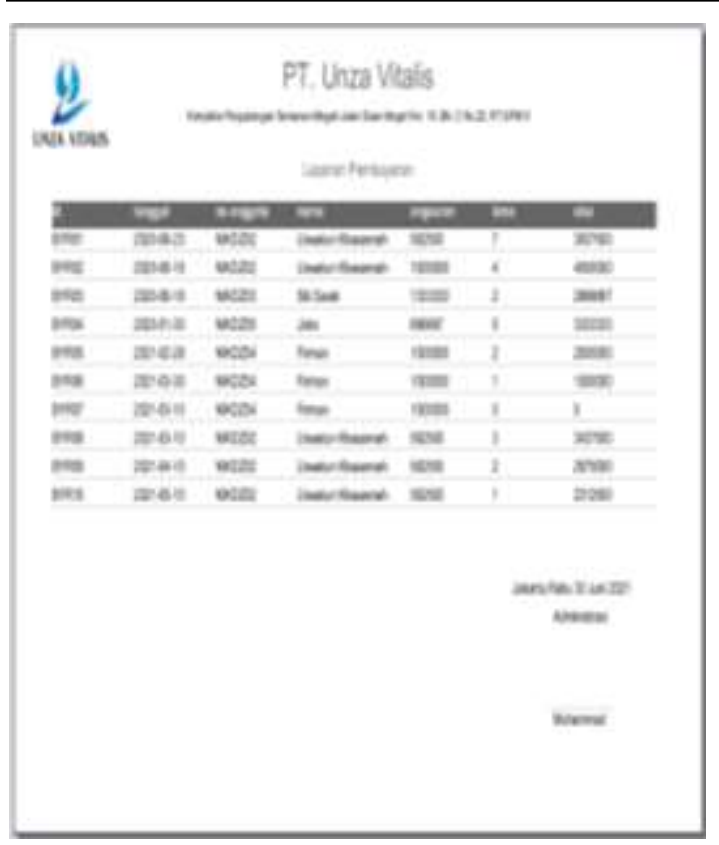

Gambar 11. Laporan Data Pembayaran

Layar di atas menampilkan tampilan form laporan data pembayaran. Pada layar form data pembayaran digunakan untuk mengecek laporan data pembayaran terdiri No Bayar, Tgl Bayar, No Anggota, Nama Anggota, Sisa Angsuran, Angsuran dan Lama Pinjam.

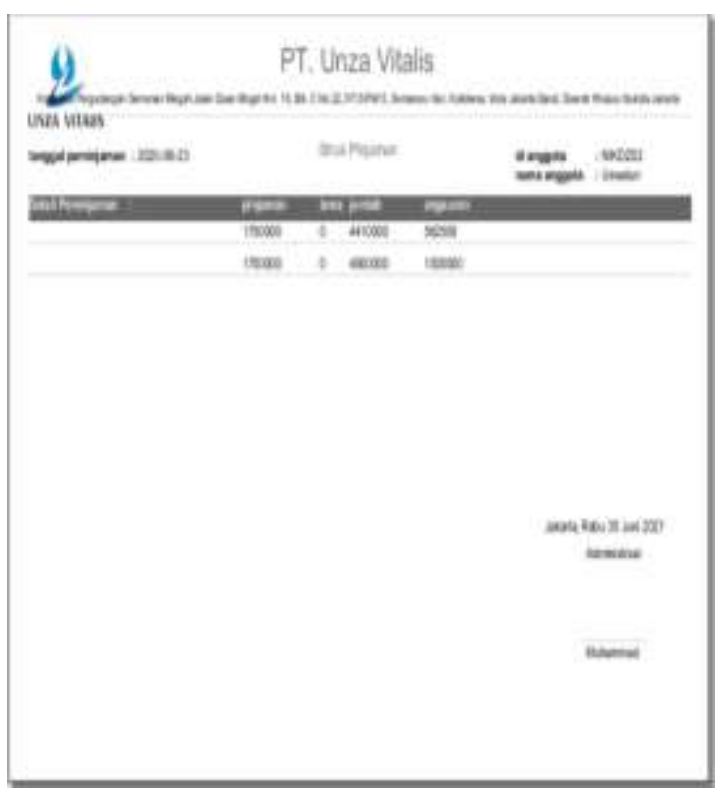

Gambar 12. Struk Pinjaman

Layar di atas menampilkan tampilan form struk pinjamaan. Pada layar form struk pinjaman digunakan untuk mengecek struk pinjaman terdiri Tanggal Pinjaman, Id Anggota, Nama Anggota, Sisa Pinjaman, Lama Pinjaman, Jumlah Pinjaman dan Angsuran.

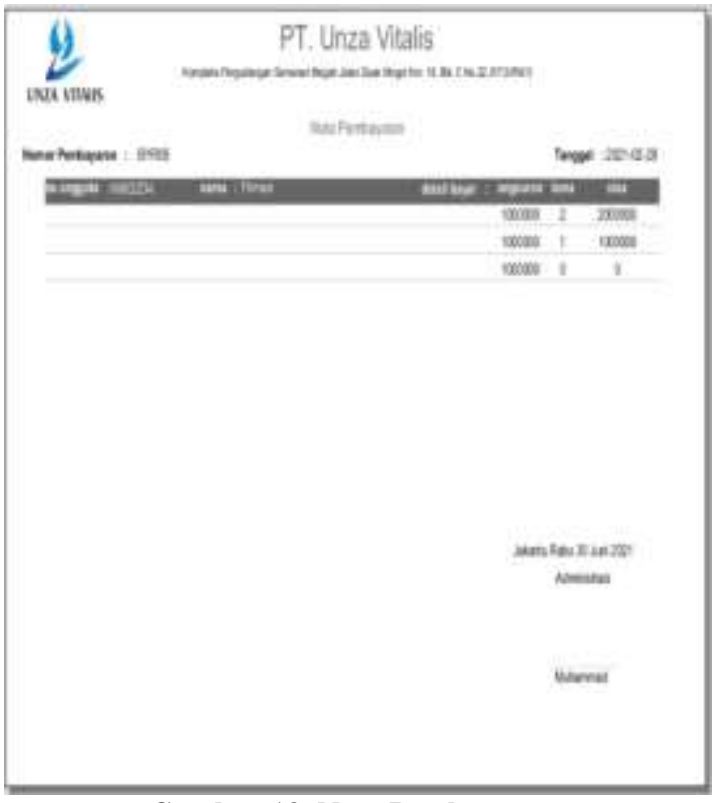

Gambar 13. Nota Pembayaran

Layar di atas menampilkan tampilan form nota pembayaran. Pada layar nota pembayaran digunakan untuk mengecek nota pembayaran terdiri Nomor Pembayaran, Tanggal, No Anggota, Nama Anggota, Angsuran, Lama Pinjaman dan Sisa Pinjaman.

\section{SIMPULAN DAN SARAN}

Sistem informasi yang menyajikan menu untuk mengelola data administrasi anggota koperasi, data simpan pinjam koperasi, data angsuran pinjaman, angsuran denda pinjaman, dan laporan-laporan sehingga memudahkan admin dalam proses pengolahan serta pencarian data. Selain itu, aplikasi ini memberikan fungsi dalam mengelola data administrasi dan simpan pinjam koperasi sehingga aplikasi ini dapat memeriksa jumlah pinjaman anggota.

Sarannya adalah sebelum sistem informasi koperasi simpan pinjam pegawai di PT. Unza Vitalis dilaksanakan, sebaiknya seluruh pihak yang terkait dalam sistem harus diberikan penjelasan dengan baik terlebih dahulu mengenai proses kerja sistem informasi koperasi simpan pinjam pegawai di PT. Unza Vitalis yang diterapkan sehingga tidak terjadi kekeliruan. Serta perlu dilakukan pelatihan terhadap penggunaan sistem tersebut kepada pengurus yang terlibat dalam aplikasi koperasi simpan pinjam pegawai ini, agar pengurus dapat mengetahui dan memahami cara kerja aplikasi yang baru. 


\section{DAFTAR PUSTAKA}

Astuti, D., \& Devitra, J. (2017). Analisis Dan Perancangan Sistem Informasi Simpan Pinjam Pada Koperasi Pegawai Negeri Iain Sultan Thaha Saifuddin Jambi. Manajemen Sistem Informasi. https://doi.org/http://dx.doi.org/10.1159 1/jurnalmsi.v12i4.xxxx

Atikah, H. R., \& Sukadi. (2013). Sistem Informasi Simpan Pinjam Pada Koperasi Wanita Putri Harapan Desa Jatigunung Kecamatan Tulakan. IJNS - Indonesian Journal on Networking and Security.

Permana, A. A. (2017). Rancangan Sistem Informasi Simpan Pinjam Pada Koperasi Guru Dan Pegawai Smp Negeri 45 Jakarta. JIKA (Jurnal Informatika), 1(2), 79-87.

https://doi.org/10.31000/jika.v1i2.1400

Prasojo, M. (2011). Pengantar Sistem Informasi Manajemen. bandung: CV. Remadja Karya.

Puspitasari, D. (2016). RANCANG BANGUN SISTEM INFORMASI KOPERASI SIMPAN PINJAM KARYAWAN BERBASIS WEB. Jurnal Pilar Nusa Mandiri.

Putra, N. (2011). Research and Development, Penelitian dan Pengembangan: Suatu Pengantar. Jakarta: PT Raja Grafindo
Persada.

Satzinger, J. W., Jackson, R. B., Burd, S. D. (n.d.). System Analysis and Design in A Changing World. USA: Cengage Learning.

Subyantoro, A. (2015). Manajemen Koperasi. Yogyakarta: Gosyen Publishing.

Sugiyono. (2016). Metode Penelitian Kuantitatif, Kualitatif dan $R \& D$. Bandung: PT Alfabet.

Sujono, S., Mayasari, M. S., \& Koloniawan, K. (2019). PROTOTIPE APLIKASI SIMPAN PINJAM PADA KOPERASI DARMA KARYA PANGKALPINANG BABEL. Jurnal Sisfokom (Sistem Informasi Dan Komputer). https://doi.org/10.32736/sisfokom.v8i1. 609

Sutabri, T. (2012). Analisis Sistem Informasi. Yogyakarta: Andi.

Tyoso, J. S. P. (2016). Sistem Informasi Manajemen. Yogyakarta: DeePublish.

Wati, H. K., \& Siahaan, K. (2017). Analisis Dan Perancangan Sistem Informasi Koperasi Simpan Pinjam Berbasis Web Pada Mts Negeri Talang Bakung Kota Jambi. Jurnal Manajemen Sistem Informasi. 